\title{
Comparação entre a técnica de substituição do ligamento redondo por implante de fascia lata bubalina preservada em glicerina e o uso de pino transarticular na redução e na estabilização da luxação coxofemoral experimentalmente induzida em cães
}

\author{
[Comparation between the technique of substitution of the round ligamentum by glycerin-preserved bubaline fascia \\ lata implant and the use of transarticular pin in the redution and stabilization of \\ experimentally induzed coxofemoral luxation in dogs] \\ D.B. Sia ${ }^{1}$, C. Gomes ${ }^{1}$, E.A. Contesini ${ }^{1 *}$, A.C. Both ${ }^{2}$, E.M. Souza ${ }^{2}$, M.P. Ferreira ${ }^{1}$, \\ H.M. Gomes ${ }^{1}$, L.M. Colomé ${ }^{1}$, R.R. Ferreira ${ }^{1}$ \\ ${ }^{1}$ Faculdade de Veterinária - UFRGS \\ Av. Bento Gonçalves, 9090 \\ 91540-000 - Porto Alegre, RS \\ ${ }^{2}$ Médico veterinário autônomo
}

\begin{abstract}
RESUMO
Compararam-se duas técnicas cirúrgicas de redução e estabilização da articulação coxofemoral experimentalmente luxada em cães. Dois grupos de animais, submetidos às respectivas técnicas após a indução cirúrgica da luxação, foram acompanhados clínica e radiograficamente por um período de 60 dias, findos os quais, realizaram-se avaliações macroscópica e histológica e teste de tensiometria das articulações. Cada grupo foi constituído por oito animais, clinicamente sadios, com pesos entre 5 e $20 \mathrm{~kg}$. Os animais submetidos ao implante de fáscia apresentaram, ao exame físico, evolução da deambulação significativamente precoce em relação aos do grupo submetido ao implante de pino de Steinmann, além de menor grau de atrofia muscular. Os testes de tensiometria, as avaliações macroscópicas e radiográficas e os exames histológicos não diferiram entre os grupos, evidenciando também que ambas as técnicas não geraram alterações deletérias à articulação operada. Conclui-se que a técnica de estabilização da articulação coxofemoral com implante de fascia lata foi clinicamente eficaz e vantajosa quando comparada à técnica do pino transarticular.
\end{abstract}

Palavras chave: cão, articulação, membrana biológica, ortopedia

\begin{abstract}
It was compared both surgical techniques of reduction and stabilization of experimentally luxated coxofemoral join in dog. Two groups were submitted to the techniques after surgical induction of the luxation. All animals were clinically and radiografically observed during 60 days. After that, a macroscopic study, an histological exam, and a tensiometry test in the articulations were performed. Each group had eight healthy animals, weighting from 5 to $20 \mathrm{~kg}$. The most important advantage was related to the deambulation, which the animals submited to the facia lata implant showed a faster evolution after the surgery at the physical exam, and muscular atrophy in a smaller degree. The tensiometry tests, the radiographic and the histological exams did not present important differences between both groups, but they were useful to show that the two techniques did not cause alterations in the studied articulation. It can be concluded that the stabilization of the coxofemoral articulation using bubaline fascia lata implant was clinically efficient and more advantageous compared to the transarticular pin technique.
\end{abstract}

Keywords: dog, joint, biological membrane, orthopedia

Recebido em 26 de maio de 2008

Aceito em 6 de abril de 2009

*Autor para correspondência (corresponding author)

E-mail: emerson.contesini@ufrgs.br 


\section{INTRODUÇÃO}

As luxações coxofemorais surgem principalmente após traumatismo externo na pelve, sendo o tipo de luxação mais comum em cães, representando $90 \%$ das luxações nesta espécie (Tomlinson, 1996; Meheust et al., 2001; Ozaydin et al., 2003). O ligamento redondo sempre está rompido ou avulsionado nas luxações coxofemorais, assim como a cápsula deve encontrar-se rasgada para que ocorra o deslocamento da cabeça femoral (Denny e Butterworth, 2000; Rodaski et al., 2002).

A redução da luxação coxofemoral objetiva a estabilização da articulação para que ocorra reparo do tecido mole e recuperação funcional do membro (Piermattei e Flo, 1999). Inicialmente, faz-se redução fechada e fixação externa com bandagens, entretanto, nos casos em que há grande lesão dos tecidos moles por longo período de tempo, geralmente ocorre recidiva da luxação da articulação, mesmo se bem-sucedida a redução fechada. A recidiva pode alcançar $50 \%$ e até $70 \%$ dos casos (Mehl, 1988; Mehenst et al., 2001; Ozaydin et al., 2003).

A redução aberta é indicada principalmente em animais com recidiva da luxação, em luxações com complicações, como fraturas e avulsão, ou quando a lesão ocorreu há mais de cinco dias (Evers et al., 1997). As reduções abertas apresentam taxa de sucesso entre $73 \%$ e $100 \%$ (Hammer, 1980), sendo também indicadas para animais politraumatizados que necessitam retorno precoce da funcionalidade do membro (Meij et al., 1992).

Alguns métodos têm sido descritos para restabelecer a estabilidade coxofemoral conferida originalmente pelo ligamento redondo, pela cápsula articular e pelo tecido periarticular (Meij et al., 1992; Denny e Butterworth, 2000). Os procedimentos cirúrgicos podem ser divididos em extra-articulares e intra-articulares, sendo alguns desses a capsulorrafia, o fixador externo flexível, a transposição do trocânter maior, o pino em cavilha, a artroplastia acetabulofemoral com pericárdio bovino, o loop pediculado de fascia lata e a prótese coxofemoral (Fossun, 1997; Johnston, 1999; Moya, 2001; Rodaski et al., 2002; Arias et al., 2004).
Os objetivos deste trabalho foram propor uma técnica alternativa de redução de luxação e estabilização da articulação coxofemoral em cães, mediante substituição do ligamento redondo por implante preservado em glicerina a 98\% de fascia lata de búfalo e comparar sua eficácia, utilizando a técnica do pino transarticular como referencial.

\section{MATERIAL E METÓDOS}

Foram utilizados 16 cães, sem raça definida, sem distinção de sexo, adultos, hígidos, com pesos entre 5 e $20 \mathrm{~kg}$, distribuídos em dois grupos de oito animais, de acordo com a técnica de estabilização empregada: grupo fáscia e grupo pino. Os animais foram submetidos ao exame clínico geral e à avaliação da articulação coxofemoral por meio de inspeção, palpação e realização de exames específicos como os sinais de Ortolani e de Barlow, o teste de Bardens e o teste da estação bípede ou Stand Test. Realizouse também avaliação radiográfica da articulação coxofemoral com o paciente em posição ventrodorsal com os membros estendidos e aduzidos, de modo que os joelhos ficassem totalmente estendidos, paralelos entre si e à coluna vertebral, e as patelas centralizadas, e mensurou-se o ângulo de Norberg. Os cães que apresentaram algum tipo de anormalidade nas avaliações pré-operatórias não foram incluídos no experimento. Os animais selecionados foram alojados, após vermifugação e vacinação, em um canil, onde foram mantidos até o final do experimento com alimentação à base de ração industrial balanceada e água à vontade.

Foi utilizada como medicação pré-anestésica a associação de maleato de acepromazina $\left(0,1 \mathrm{mg} \cdot \mathrm{kg}^{-1}\right)$ e cloridrato de petidina $\left(3,5 \mathrm{mg} \cdot \mathrm{kg}^{-}\right.$ $\left.{ }^{1}\right)$, administrados concomitantemente por via intramuscular. A indução anestésica foi realizada com propofol (4mg. $\left.\mathrm{kg}^{-1} \mathrm{IV}\right) 20$ minutos após. Ao atingir o estágio III de Guedel, procedeu-se à intubação orotraqueal para manutenção da anestesia com halotano em 100\% de oxigênio, em circuito semifechado. Em associação à anestesia inalatória, promoveu-se a anestesia epidural lombossacral (L7-S1) com cloridrato de lidocaína $2 \%\left(2 \mathrm{mg} \cdot \mathrm{kg}^{-1}\right)$ com bupivacaína $0,5 \%$ $\left(0,5 \mathrm{mg} \cdot \mathrm{kg}^{-1}\right)$. 
Realizou-se tricotomia ampla, que se estendeu da $13^{a}$ costela até a tuberosidade isquiática e da região dos processos espinhosos, dorsalmente, até o terço distal da tíbia. Os procedimentos foram sempre efetuados no membro posterior direito. A abordagem cirúrgica foi realizada mediante incisão craniolateral e tenotomia dos músculos glúteos de acordo com Piermattei e Greeley (1988), a partir da técnica de Brown. A cápsula articular e o músculo capsular foram incisados na linha média, entre a borda acetabular e o colo femoral; o ligamento redondo foi seccionado com tesoura de Metzembaun para promover a luxação da articulação. Com a cabeça femoral e acetábulo luxados e devidamente expostos, iniciaram-se os procedimentos de redução e estabilização cirúrgicas propostos no experimento.

Para a estabilização por meio da substituição do ligamento redondo por implante de fascia lata de búfalo, confeccionou-se um túnel da fovea capitis até o trocânter maior com uma broca e furadeira elétrica (Fig. 1A e B). Um outro túnel de mesmo diâmetro foi feito na fossa acetabular (Fig. 1C e D). O diâmetro das brocas variou de acordo com o peso do animal, conforme Moya (2001).

Dobrou-se uma das extremidades de um fio de Kirschner (1mm) para formar uma alça para fixação e posicioná-lo no interior do túnel femoral, de forma que entrasse pela fovea capitis e emergisse no trocânter maior. Fixou-se, então, o implante de fascia lata à alça do fio de Kirschner com um fio de mononáilon 2-0 e ponto simples isolado. A seguir, o fio de Kirschner foi tracionado até o implante emergir pela fovea capitis (Fig. 2A e B). Outro fio de náilon foi fixado a um fio de Kirschner moldado em forma de gancho, o qual foi introduzido pelo túnel acetabular (Fig. 2C e D), direcionado no sentido de margear a face pélvica até emergir na borda dorsal do acetábulo e ser posteriormente retirado, deixando apenas o fio de náilon, ao qual foi presa a extremidade do retalho, que emergiu por meio da fovea capitis.

O retalho foi, em seguida, tracionado pelo fio de náilon de modo que passasse pela borda dorsal do acetábulo (Fig. 3A e B). As extremidades do retalho foram tracionadas e fixadas conjuntamente no trocânter maior com fio de náilon 2-0 ou 0 , de acordo com o peso do animal, com pontos de Sultan (Fig. 3C e D). Suturaramse os músculos glúteos às suas inserções, empregando pontos interrompidos de Sultan e fio de náilon 2-0. O músculo tensor da fascia lata e a própria fascia lata foram devidamente reaproximados com sutura contínua simples e fio poliglactina 2-0. A redução de espaço morto foi realizada com sutura contínua simples e poliglactina 2-0, e a pele foi suturada com pontos simples isolados e fio de náilon 3-0.

Para a estabilização mediante colocação de pino de Steinmann transarticular, realizaram-se o mesmo procedimento anestésico e a mesma abordagem cirúrgica descrita anteriormente, porém a estabilização foi conferida pela introdução de um pino de Steinmann a partir do trocânter maior em direção à fovea capitis, com uma parafusadeira elétrica, e redução da luxação com penetração do pino pela fossa acetabular até cerca de 3 a $7 \mathrm{~mm}$ no interior da pelve (Fig. 4A e B). O diâmetro dos pinos foi escolhido de acordo com o peso dos animais e tamanho da cabeça femoral, seguindo as recomendações de Hunt e Henry (1985). A síntese seguiu o relato anterior.

Após 21 dias, os animais do grupo que utilizou o pino transarticular foram submetidos à nova cirurgia para retirada dos pinos. $\mathrm{O}$ procedimento ocorreu sob o mesmo protocolo anestésico, com exceção da anestesia epidural. Realizaram-se incisão da pele de $1 \mathrm{~cm}$ sobre o pino, divulsão do subcutâneo até a sua visualização e apreensão e extração com alicate de pressão. A pele foi suturada com náilon 3-0, ponto simples isolado.

No pós-operatório, os animais receberam meloxicam $0,2 \mathrm{mg} \cdot \mathrm{kg}^{-1}$ por via oral, a cada 24 horas, durante cinco dias, enrofloxacina $5 \mathrm{mg} . \mathrm{kg}^{-}$ 1 , a cada 12 horas, por via oral durante sete dias, e tramadol $2 \mathrm{mg} . \mathrm{kg}^{-1}$, a cada oito horas, por via intramuscular durante dois dias. Permaneceram alojados no canil, em gaiolas individuais de $1 \mathrm{~m}^{2}$, durante os sete primeiros dias de pós-operatório, e em convívio com outros cães do projeto, acomodados em um canil com $8 \mathrm{~m}^{2}$.

Os animais foram submetidos a exame clínico específico das articulações coxofemorais, com realização de inspeção e palpação para se observar a movimentação das articulações, com periodicidade semanal. Mensurou-se o perímetro dos membros afetados e contralaterais de todos os animais com fita métrica colocada na região 
de terço médio do fêmur, no primeiro e no $60^{\circ}$ dia, para avaliação da atrofia muscular. Diariamente, desde o primeiro dia após a cirurgia e até 60 dias, realizou-se avaliação deambulatória, por inspeção, baseada na tabela de claudicação de Tudury e Raiser (1985). Foram realizadas radiografias com incidência ventrodorsal das articulações coxofemorais de todos os cães no pós-operatório imediato, no $21^{\circ}$ dia e no $60^{\circ}$ dia de pós-operatório, para avaliação de a congruência articular e da presença de enfermidade articular degenerativa ou outras alterações. Aos 60 dias, os animais foram sacrificados utilizando-se tiopental sódico na dose de 40mg. $\mathrm{kg}^{-1}$ por via endovenosa e posterior administração de sulfato de magnésio diluído em água na proporção 1:10, por via endovenosa, até a completa parada cardiorrespiratória.

No exame post mortem, fez-se avaliação direta da congruência da articulação, da mobilidade, das alterações degenerativas, da formação de fibroses e osteófitos e do implante. As articulações foram avaliadas por microscopia óptica, de acordo com o respectivo grupo. Foram examinados a parte do acetábulo associada aos implantes, a cabeça e o colo do fêmur, com os trajetos intraósseos. A descalcificação foi realizada pelo Método de Cajal, utilizando-se ácido nítrico a 3\%. Os fragmentos ósseos, após descalcificados, assim como a cápsula articular, foram submetidos aos procedimentos de rotina histológica, corados pelos métodos da hematoxilina-eosina e tricrômico de Masson, e examinados por microscopia óptica.

A resistência à tração foi testada com máquina universal de ensaios mecânicos ${ }^{1}$ com célula de carga de 50kgf, na Faculdade de Engenharia Mecânica da Universidade Federal do Rio Grande do Sul, com o objetivo de avaliar a capacidade máxima de tensão de cada articulação antes de sua ruptura, quando submetida a estresse intenso de tração. Para realização dos testes, foram coletados três pares de articulações de cada grupo, que foram descartadas para o exame macroscópico direto. Cada par da articulação correspondeu a um animal, membro operado e membro contralateral. A coleta foi realizada por osteotomia com ostótomo no terço médio da diáfise femoral, no íleo (caudal ao sacro) e na sínfise púbica. A musculatura foi removida por dissecção com pinça anatômica e bisturi 4 com lâmina $\mathrm{n}^{\circ}$ 24. Foram realizados três orifícios adjacentes à articulação para fixação de fitas plásticas - um posicionado no trocânter maior, em sentido craniocaudal, e os outros dois posicionados cranial e caudal ao acetábulo, em sentido lateromedial. As fitas plásticas funcionaram como pontos de fixação entre a articulação e o tensiômetro (Fig. 5). Após a fixação na máquina, iniciava-se a tração em sentido longitudinal até que houvesse a ruptura da cápsula articular e do ligamento redondo, sendo registrado o valor máximo necessário para a ruptura total.

Utilizou-se análise de variância múltipla complementada pelo teste Tukey de comparações múltiplas e nível de significância de $5 \%$ para as variáveis deambulação e atrofia muscular. Para os resultados da tensiometria, utilizou-se o teste $\mathrm{t}$ para amostras pareadas com $\mathrm{P}=0,558$

\section{RESULTADOS E DISCUSSÃO}

Os animais do grupo fáscia apresentaram evolução da deambulação e uso funcional do membro operado em tempo significativamente menor $(\mathrm{P}<0,05)$ que os animais do grupo pino. $\mathrm{O}$ tempo médio que cada grupo levou para atingir os diferentes graus de claudicação encontra-se na Fig. 6.

A atrofia muscular observada ao final dos 60 dias foi significativamente menor $(\mathrm{P}<0,05)$ no grupo fáscia quando comparada à atrofia apresentada pelo grupo pino. A Fig. 7 representa as diferenças médias de atrofia muscular dos dois grupos.

À palpação, a técnica do pino transarticular evidenciou movimentação restrita, principalmente quanto à adução, abdução e rotação da articulação coxofemoral, até o momento de retirada do pino. A técnica de substituição do ligamento resultou em movimentação fisiológica articular.

${ }^{1}$ EMIC, modelo DL 10.000 - São José dos Pinhais, Brasil. 


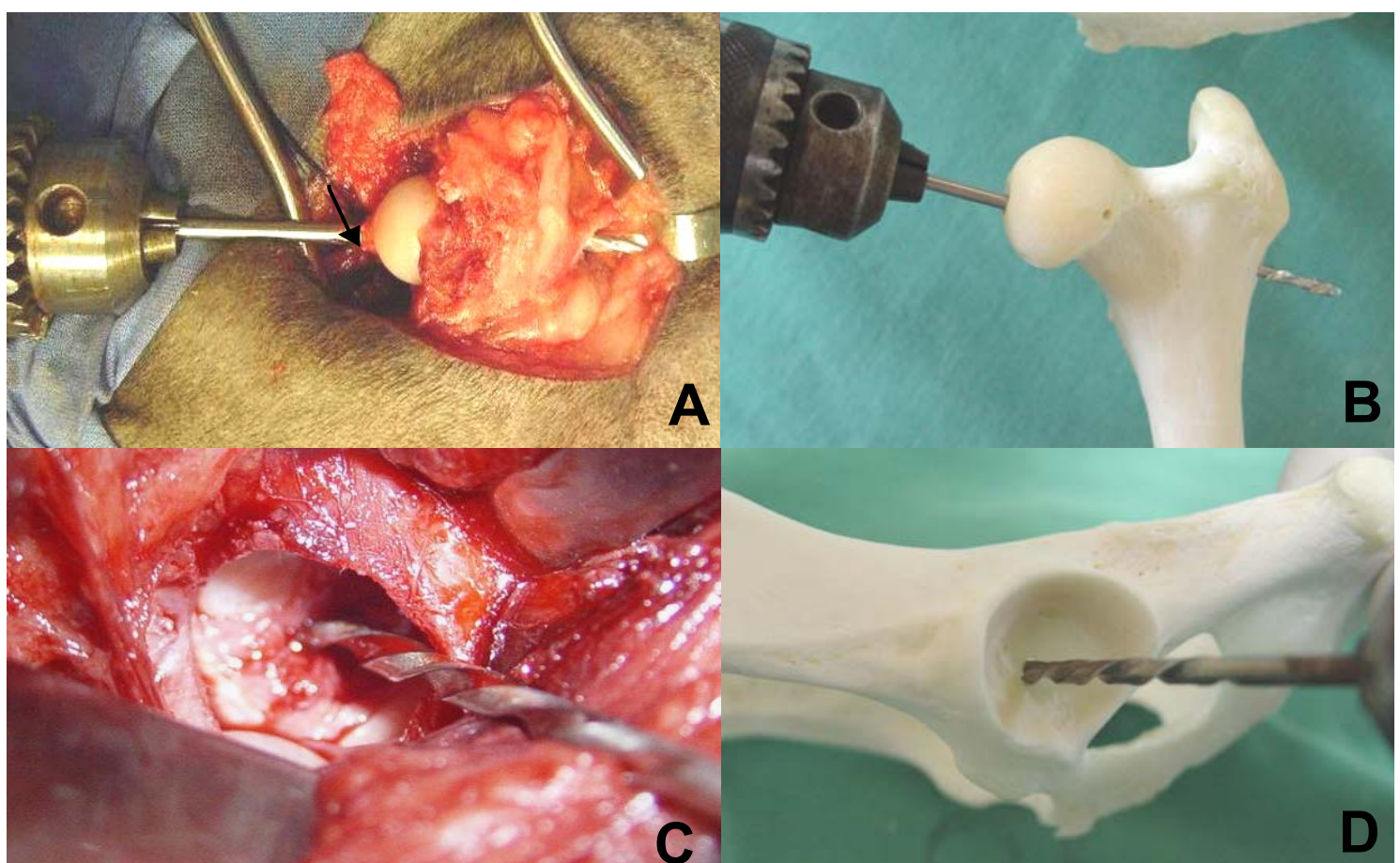

Figura 1. A: Perfuração óssea com furadeira e broca entrando pela fovea capitis (seta) e emergindo no trocânter. B: Imagem in vitro da perfuração óssea com furadeira e broca entrando pela fovea capitis. C: Perfuração óssea com furadeira e broca na fossa acetabular para passagem do implante. D: Imagem in vitro da perfuração óssea com furadeira e broca na fossa acetabular.

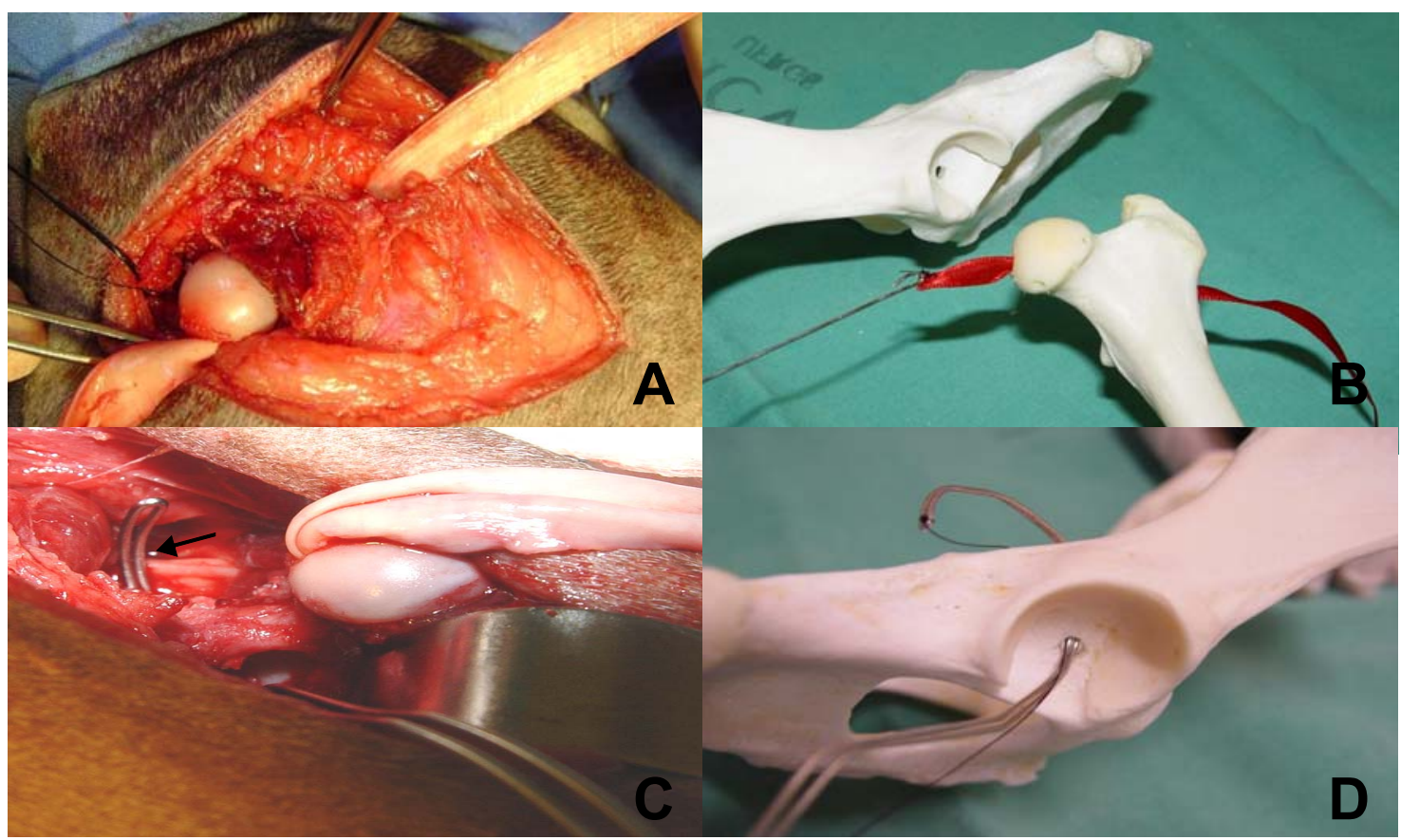

Figura 2. A: Implante de fascia lata bubalina entrando pelo trocânter maior no túnel ósseo e emergindo na fovea capitis. B: Imagem esquemática da passagem do implante de fascia lata bubalina pelo túnel ósseo, com entrada pelo trocânter maior e saída na fovea capitis. C: Fio de Kirschner moldado em forma de gancho passando pela perfuração do acetábulo e emergindo na borda dorsal acetabular. D: Imagem esquemática do fio de Kirschner em forma de gancho passando pela perfuração do acetábulo e emergindo na borda dorsal acetabular. 


\section{Sai et al.}

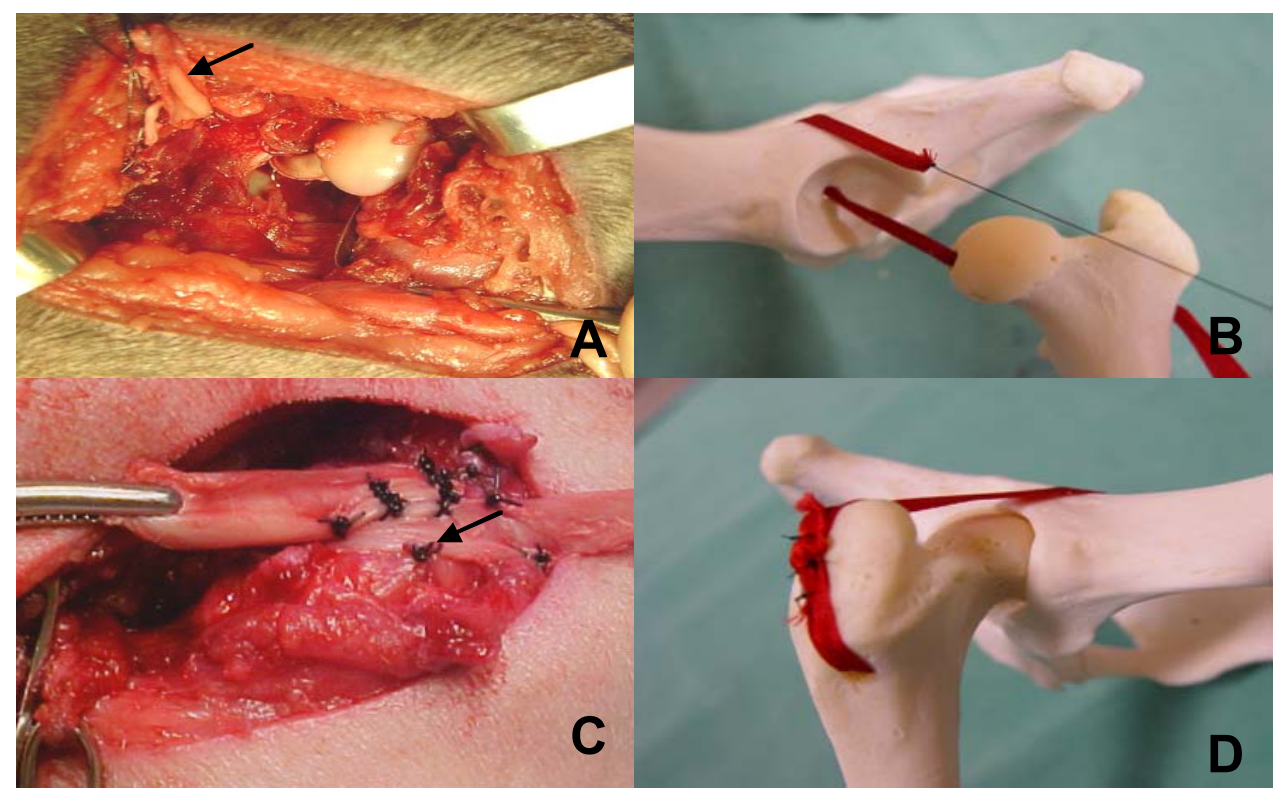

Figura 3. A: Retalho de fascia lata de búfalo entrando na fossa acetabular e emergindo na borda dorsal do acetábulo (seta). B: Imagem esquemática do retalho de fascia lata de búfalo entrando na fossa acetabular e emergindo na borda dorsal do acetábulo. C: Extremidades do retalho (seta) fixadas no trocânter maior com pontos Sultan e fio de náilon. D: Imagem esquemática das extremidades do retalho fixadas no trocânter maior com pontos Sultan e fio de náilon.

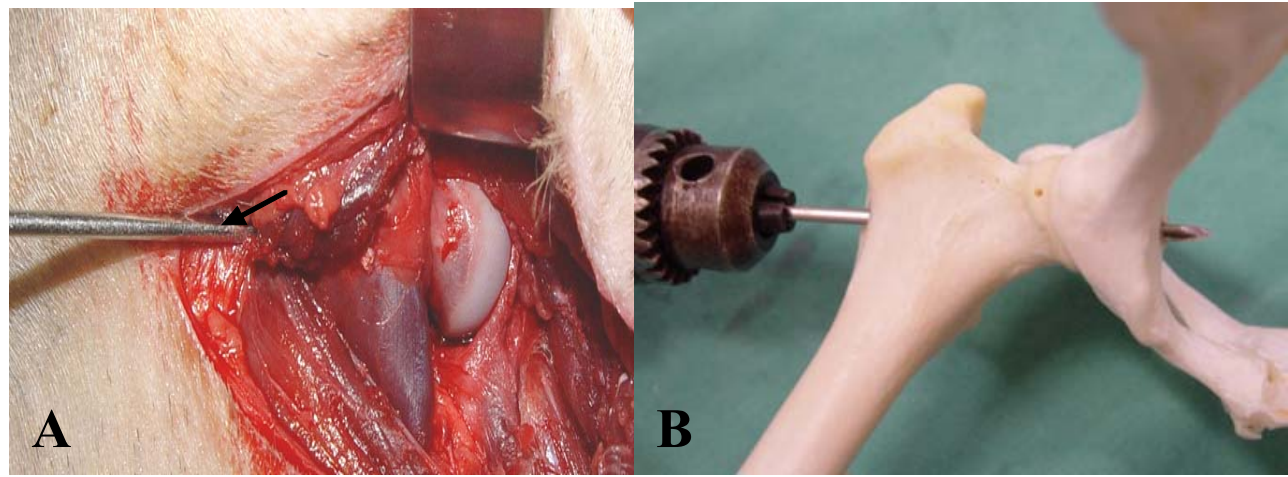

Figura 4. A: Introdução de pino de Steinmann (seta) a partir do trocânter maior em direção à fovea capitis e fossa acetabular. B: Imagem esquemática da introdução do pino de Steinmann a partir do trocânter maior, passando pela fovea capitis e fossa acetabular até penetrar cerca de $5 \mathrm{~mm}$ no interior da pelve.

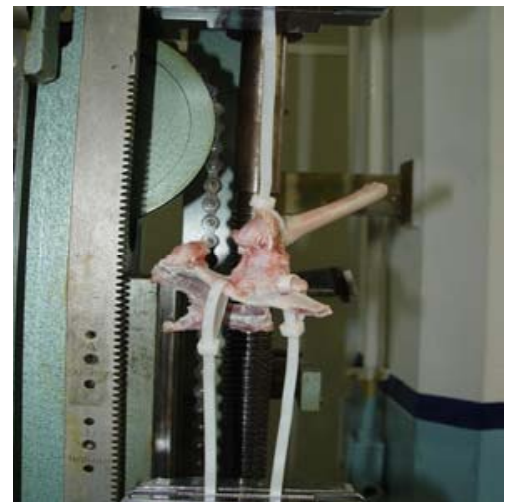

Figura 5. Articulação do quadril posicionada em tensiômetro, fixada por fitas plásticas presas ao trocânter maior e ao coxal, para teste de resistência em cães. 


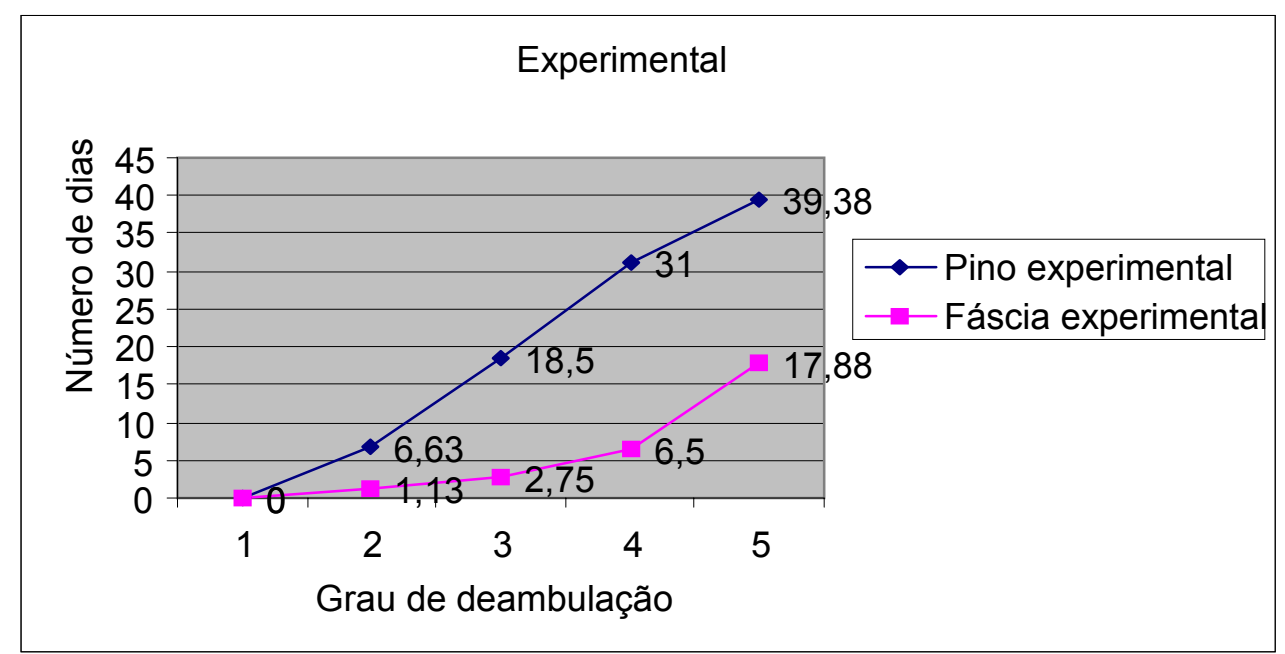

Figura 6. Evolução da deambulação em cães, segundo os grupos fáscia e pino.

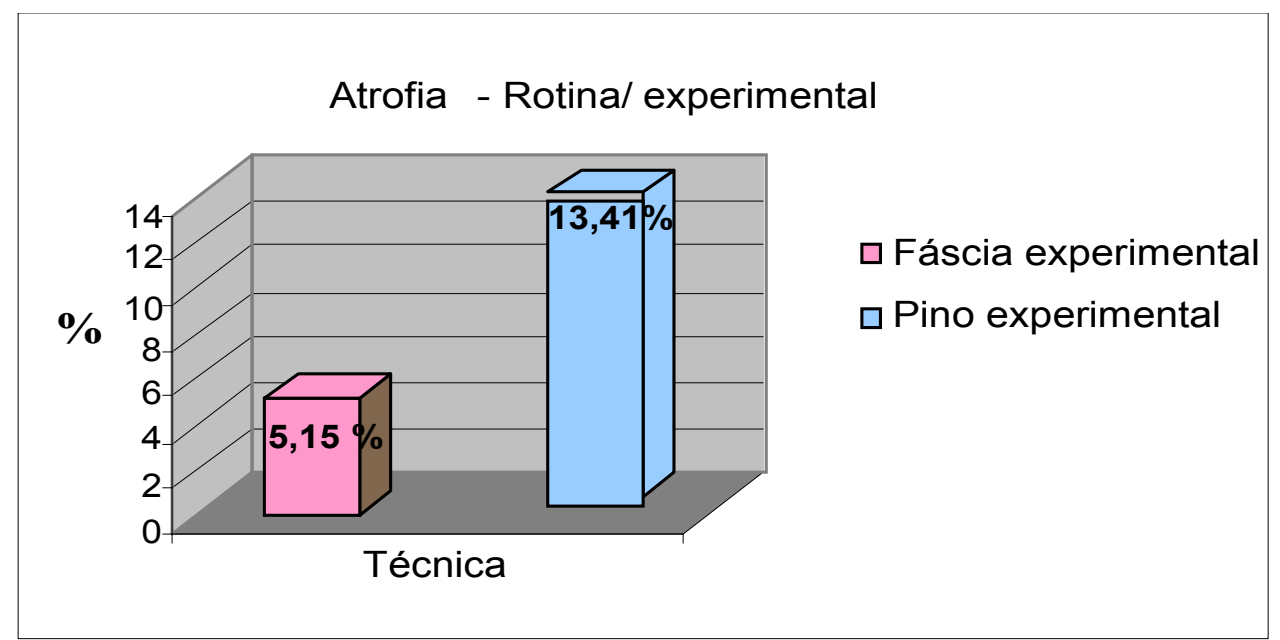

Figura 7. Porcentagem de atrofia muscular em cães segundo os grupos fáscia e pino.

Nas avaliações radiográficas periódicas, foi observada alteração apenas em um cão do grupo pino, no qual se visualizou formação de imagem semelhante a calo ósseo na face pélvica do acetábulo, referente ao ponto de perfuração do pino de Steinmann. Nos demais cães, observaram-se congruência articular preservada, ausência de sinais radiográficos sugestivos de doença articular degenerativa e região do túnel femoral com radioluscência aumentada em relação ao fêmur.

O exame macroscópico das articulações operadas não apresentou alterações quanto à observação da congruência articular e integridade das superfícies articulares. Nos cães submetidos à técnica de substituição do ligamento, observouse a presença de estrutura fibrosa, semelhante ao implante, íntegra em $90 \%$ das articulações operadas. O local da incisão capsular revelou-se espessado devido à proliferação fibrosa cicatricial, em ambos os grupos, não sendo observadas outras alterações na cápsula articular. Foi constatada alteração macroscópica apenas no cão que apresentou alteração radiográfica. Nele observou-se proliferação óssea circundando o túnel acetabular na face pélvica do acetábulo direito.

O exame histológico das articulações do grupo fáscia evidenciou proliferação de tecido conjuntivo abundante com neovascularização e 
áreas com formação de periósteo periférico às perfurações. Nas articulações do grupo pino, visualizaram-se área cística, correspondendo à região do pino previamente retirado, e acentuada proliferação de tecido conjuntivo, com neovascularização, e áreas com neoformação de cartilagem, sugerindo calo ósseo e periósteo evidente.

A comparação dos valores máximos, em quilogramas necessários para que houvesse a ruptura total da cápsula articular e do ligamento ou implante, mostrou não haver diferença significativa na tensiometria dos membros operados e contralaterais. Os resultados da tensiometria também indicaram que ambas as técnicas conferiram resistência à tração nas articulações que sofreram o procedimento cirúrgico, igual à dos membros não-operados.

A utilização de fascia lata bubalina como implante não apresenta relato anterior em literatura consultada, todavia sua escolha teve base em experimentos que utilizaram, com sucesso, fascia lata autóloga para reparos ortopédicos em cães (Bergamo et al., 2000; Silva et al., 2000; Moya, 2001; Brandão et al., 2002) e também em estudos que utilizaram pericárdio bovino conservado em glicerina $98 \%$ para estabilização da articulação coxofemoral. Apesar dos relatos de sucesso da utilização de fascia lata autológa, optou-se pelo uso de membrana biológica conservada, pois a obtenção do enxerto autógeno culmina em maior trauma cirúrgico e potenciais cicatrizes, que comprometem a estética da cirurgia, além de resultar em um maior tempo anestésico, representando maior risco ao animal (Rodaski et al., 2002).

A glicerina $98 \%$ foi escolhida como meio de conservação, pois apresenta propriedades antissépticas e rápida ação desidratante e fixadora, mantendo a textura original dos tecidos por ela conservados, além de possuir efeito redutor sobre a antigenicidade (Alvarenga, 1992; Rabelo, 2004). Rabelo (2004) não verificou diferença significativa no ponto de ruptura dos centros tendíneos diafragmáticos de bovinos conservados em glicerina $98 \%$ por 30 dias e nos in natura, indicando não haver alterações significativas nas características físicas do material conservado.
A técnica de substituição do ligamento redondo proposta neste trabalho foi adequada para conferir congruência e manutenção da estabilidade articular, como observado por Moya (2001) na substituição do ligamento redondo por fascia lata autóloga. Neste estudo, não se associou a reparação da cápsula articular obtida por meio de pontos de sutura, conforme preconizado por Lubbe e Verstraete (1990), nem pela fixação da fascia lata na região craniodorsal da cápsula articular com pontos simples isolados, de acordo com Zaslow e Hanson (1975), nem a partir da associação das duas técnicas, segundo Moya (2001). Pode-se afirmar, portanto, que a congruência e a estabilidade articular foram conferidas, inicialmente, apenas pelo implante heterólogo. Segundo Piermattei e Flo (1999), o ligamento redondo substituído deve ser mantido por tempo suficiente para permitir o reparo da cápsula articular e cicatrização dos tecidos moles adjacentes. Além de manter a congruência e a estabilidade da articulação, a técnica também permitiu o apoio imediato e o uso funcional precoce do membro acometido, assim como relataram Manley (1993) e Moya (2001). O apoio imediato após substituição do ligamento redondo também foi observado por Hõim et al. (2006). O uso funcional do membro ocorreu mais rapidamente neste experimento quando comparado aos resultados obtidos por Lubbe e Verstraete (1990), Rodaski et al. (2002) e Hõim et al. (2006).

A técnica do pino transarticular revelou-se eficaz na redução e na estabilização das luxações, sendo os resultados semelhantes aos encontrados por Andrioli (2000), quanto à ausência de recidiva. A remoção do pino no $21^{\circ}$ dia seguiu o preconizado por Hunt e Henry (1985) para redução de luxação coxofemoral em animais displásicos, e foi adotada por revelar-se, em tese, mais segura, permitindo maior tempo de estabilidade articular e, consequentemente, melhor consolidação da cicatrização capsular e dos tecidos periarticulares.

Histologicamente, as articulações do grupo pino apresentaram aspectos de reação inflamatória semelhantes aos do grupo fáscia, porém, visualizaram-se também áreas com neoformação de cartilagem, sugerindo a formação de calo ósseo, o que provavelmente ocorreu pelo trauma constante causado pela fixação rígida do pino de Steinmann. Segundo Meij et al. (1992), a 
permanência do pino também pode levar a outras alterações como a osteoartrose.

Os grupos pino e fáscia apresentaram resultados semelhantes no sentido de confirmar ser a cápsula articular o elemento que dá estabilidade primária à articulação coxofemoral, conforme descrito por Trostel et al. (2000), até porque nos animais do grupo pino não havia ligamento para reforçar tal resistência. Além disso, é importante ressaltar que em todos os testes de tensiometria, a medida maior em quilogramas era atingida no ponto de ruptura da cápsula, não representando a ruptura do ligamento ou da fáscia, em qualquer momento, uma medida superior à necessária para a ruptura capsular. A observação de Goelzer (2001) de que tanto a cápsula como o ligamento redondo são estruturas bastante resistentes foi confirmada neste estudo, mas comprovou-se ser a cápsula articular a mais resistente das duas estruturas. Constatou-se também que, apesar do espessamento capsular das articulações operadas, tal fato não implicou aumento significativo da resistência.

\section{CONCLUSÕES}

Ambas as técnicas são eficazes para estabilizar a articulação coxofemoral após redução da luxação, permitindo o retorno ao uso funcional do membro acometido. A técnica de substituição do ligamento redondo por fascia lata de búfalo resultou na evolução mais rápida da deambulação, menor atrofia muscular, com amplitude de movimentos articulares idêntica ao fisiológico, e a não necessidade de uma segunda intervenção cirúrgica. Microscopicamente, a técnica do pino transarticular apresentou reações mais evidentes que a técnica de substituição do ligamento redondo.

\section{REFERÊNCIAS BIBLIOGRÁFICAS}

ALVARENGA, J. Possibilidades e limitações da utilização de membranas biológicas preservadas em cirurgia. In: DALECK, C.R. (Ed). Tópicos em cirurgia de cães e gatos. Jaboticabal: FUNEP - UNESP, 1992. p.33-39.

ANDRIOLI, L.G. Luxações coxofemorais traumáticas: análise da técnica de fixação transarticular e dos aspectos relacionados ao diâmetro ideal do pino. 2000. 38f. Dissertação
(Mestrado) - Universidade Federal de Santa Maria, Santa Maria.

ARIAS, S.A.; REZENDE, C.M.F.; ALVAREZ, A. et al. Prótese coxofemoral em cães: relato de dois casos. Arq. Bras. Med. Vet. Zootec., v.56, p.618-622, 2004.

BERGAMO, F.M.M.; IAMAGUTI, P.; BIASI, F. Acetabuloplastia e reconstituição do ligamento da cabeça do fêmur com autoenxerto de fascia lata para o tratamento da displasia coxofemoral Estudo experimental em cães. In: CONGRESSO BRASILEIRO DE CIRURGIA E ANESTESIOLOGIA VETERINÁRIA, 4., 2000, Goiânia. Anais... Goiânia: Editora da UFG, 2000. p.61. (Resumo).

BRANDÃO, C.V.S.; IAMAGUTI, P.; FIGUEIREDO, L.M.A. Substituição do ligamento da cabeça do fêmur com auto-enxerto de fascia lata na luxação coxofemoral em cães. Cienc. Rural, v.32, p.275-280, 2002.

DENNY, H.R.; BUTTERWORTH, S. A Guide to canine and feline orthopaedic surgery. 4.ed. Oxford: Blackwell Science, 2000. p.445-467.

EVERS, P.; JOHNSTON, G.R.; WALLACE, L.J. et al. Long-term results of treatment of traumatic coxofemoral joint dislocation in dogs: 64 cases. J. Am. Vet. Med. Assoc., v.210, p.5964, 1997.

FOSSUM, T.W. Management of joint disease. In: . Small animal surgery. St. Louis: Mosby, 1997. p.943-957.

GOELZER, L.P. Estabilização coxofemoral extra-articular após redução de luxação craniodorsal em cães. 2001. 17f. Trabalho apresentado como requisito parcial para aprovação na Disciplina Seminários em Cirurgia - Universidade Federal de Santa Maria, Santa Maria.

HAMMER, D.L. Recurrent coxofemoral luxation in fifteen dogs and one cat. J. Am. Vet. Med. Assoc., v.177, p.1018-1020, 1980.

HÕIM, R.; ANDRIANOV, V.; LENZNER, A. Use of the modified toggle pin technique for management of coxofemoral luxation in dogs: a review of literature and a report of two cases. Disponível em: $<$ http://www.eau.ee/ aps/pdf/20034/h6im.pdf $>$. Acessado em: 03 jan. 2006. 
HUNT, C.A.; HENRY, W.B. Transarticular pinning for repair of hip dislocation in the dog. A restropective study of 40 cases. J. Am. Vet. Med. Assoc., v.187, p.828-833, 1985.

JOHNSTON, S.A. Articulações. In: HARARI, J. Cirurgia de pequenos animais. Porto Alegre: Artmed, 1999. p.287-312.

LUBBE, A.M.; VERSTRAETE, F.J.M. Fascia lata loop stabilisation of the coxofemoral joint in the dog and cat. J. Small Anim. Pract., v.31, p.234-238, 1990.

MANLEY, P.A. The hip joint. In: SLATTER, D.H. Textbook of small animal surgery. 2.ed. Philadelphia: Saunders, 1993. v.2, p.1801-1804.

MEHL, N.B. A new method of surgical treatment of the hip dislocation in dogs and cats. J. Small Anim. Pract., v.29, p.789-795, 1988.

MEHEUST, P.; BOURGERON, A.; LEGEARD, F. Stabilizing traumatic coxofemoral dislocations using the Meij-Hazewinkel-Nap modified technique: a retrospective study of 64 cases. Eur. J. Comp. Anim. Pract., v.11, p.147-156, 2001.

MEIJ, B.P.; HAZEWINKEL, H.A.W.; NAP, C.R. Results of extra-articular stabilisation following open reduction of coxofemoral luxation in dogs and cats. J. Small Anim. Pract., v.33, p.320-326, 1992.

MOYA, L.E.G. Substituição do ligamento redondo femoral por "loop" pediculado de fascia lata em cães. 2001. 44f. Dissertação (Mestrado) - Universidade Federal de Santa Maria, Santa Maria.

OZAYDIN, I.; KILIÇ, E.; BARAN, V. et al. Reduction and stabilization of hip luxation by the transposition of the ligamentum sacrotuberale in dogs: an in vivo study. Vet. Surg., v.32, p.46-51, 2003.
PIERMATTEI, D.L.; GREELEY, R.G. Atlas de abordagens cirúrgicas aos ossos do cão e do gato. 2.ed. São Paulo: Manole, 1988. p.263-272.

PIERMATTEI, D.L.; FLO, G.L. Manual de ortopedia e tratamento das fraturas dos pequenos animais. São Paulo: Manole, 1999. p.496-513.

RABELO, R.E. Características físicas e microbiológicas do centro tendíneo diafragmático bovino conservado em glicerina a 98\% e no glutaraldeído a 4\%. Cienc. Anim. Bras., v.5, p.229-238, 2004.

RODASKI, S.; CUNHA, O.; DE NARDI, A.B. et al. Coxofemoral arthroplasty in dogs with conserved bovine pericardium in glycerin $98 \%$. Arch. Vet. Sci., v.7, p.179-187, 2002.

SILVA, A.M.; DEL CARLO, R.J.; FONSECA, C.C. et al. Aspectos macro e microscópicos da fascia lata utilizada como substituto autógeno do ligamento cruzado cranial. Cienc. Rural, v.30, p.275-280, 2000.

TOMLINSON, J.L. Redução das luxações coxofemorais. In: BOJRAB, M.J. Técnicas atuais de cirurgia de pequenos animais. 3.ed. São Paulo: Roca, 1996. p.622-691.

TROSTEL, C.T.; PECK, J.N.; DEHAAN, J.J. Spontaneous bilateral coxofemoral luxation in four dogs. J. Am. Anim. Hosp. Assoc., v.36, p.268-276, 2000.

TUDURY, E.A.; RAISER, A.G. Redução de fraturas distais de fêmur de cães empregando dois pinos de Steinmann em substituição aos de Rush. Cienc. Rural, v.15, p.141-155, 1985.

ZASLOW, I.M.; HANSON, P. Transplantation of the fascia lata repair dorsal capsular tears to the hip joint after traumatic dislocation. Vet. Med. Small Anim. Clin., v.70, p.69-71, 1975. 